\title{
Silica gel and microwave-promoted synthesis of dihydropyrrolizines and tetrahydroindolizines from enaminones
}

\author{
Robin Klintworth ${ }^{1}$, Garreth L. Morgans ${ }^{1}$, Stefania M. Scalzullo ${ }^{1}$, Charles B. de Koning ${ }^{1}$, \\ Willem A. L. van Otterlo ${ }^{2}$ and Joseph P. Michael ${ }^{* 1}$
}

\section{Full Research Paper}

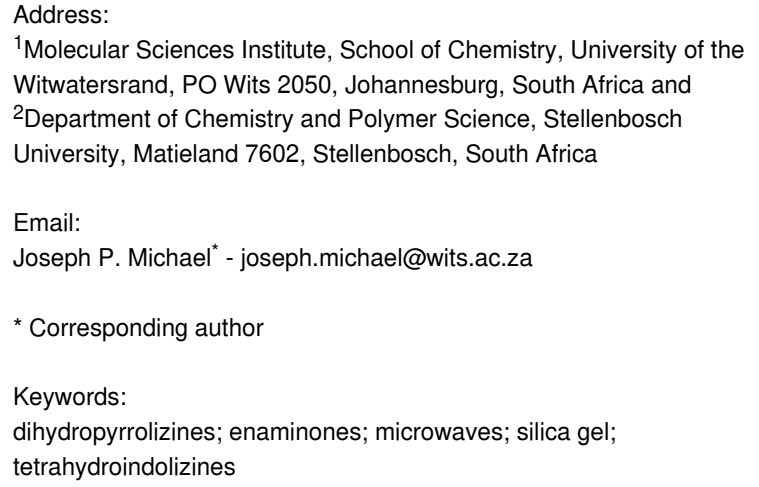

${ }^{1}$ Molecular Sciences Institute, School of Chemistry, University of the Witwatersrand, PO Wits 2050, Johannesburg, South Africa and ${ }^{2}$ Department of Chemistry and Polymer Science, Stellenbosch University, Matieland 7602, Stellenbosch, South Africa

\author{
Beilstein J. Org. Chem. 2021, 17, 2543-2552. \\ https://doi.org/10.3762/bjoc. 17.170 \\ Received: 02 August 2021 \\ Accepted: 29 September 2021 \\ Published: 13 October 2021 \\ Associate Editor: T. J. J. Müller \\ (C) 2021 Klintworth et al.; licensee Beilstein-Institut. \\ License and terms: see end of document.
}

\begin{abstract}
A wide range of $N$-(ethoxycarbonylmethyl)enaminones, prepared by the Eschenmoser sulfide contraction between $N$-(ethoxycarbonylmethyl)pyrrolidine-2-thione and various bromomethyl aryl and heteroaryl ketones, underwent cyclization in the presence of silica gel to give ethyl 6-(hetero)aryl-2,3-dihydro-1H-pyrrolizine-5-carboxylates within minutes upon microwave heating in xylene at $150{ }^{\circ} \mathrm{C}$. Instead of functioning as a nucleophile, the enaminone acted as an electrophile at its carbonyl group during the cyclization. Yields of the bicyclic products were generally above $75 \%$. The analogous microwave-assisted reaction to produce ethyl 2 -aryl5,6,7,8-tetrahydroindolizine-3-carboxylates from $(E)$-ethyl 2-[2-(2-oxo-2-arylethylidene)piperidin-1-yl]acetates failed in nonpolar solvents, but occurred in ethanol at lower temperature and microwave power, although requiring much longer time. A possible mechanism for the cyclization is presented, and further functionalization of the newly created pyrrole ring in the dihydropyrrolizine core is described.
\end{abstract}

\section{Introduction}

Partially or fully saturated variants of the pyrrolizine nucleus 1 are widely occurring motifs in natural products. The hexahydropyrrolizine (pyrrolizidine) system, for example, forms the nucleus of literally hundreds of alkaloids, many of which have gained notoriety owing to their hepatotoxicity and neurological effects on livestock and humans [1,2]. The less commonly encountered 2,3-dihydro-1 $H$-pyrrolizine framework occurs in the butterfly metabolites danaidal (2) and hydroxydanaidal (3) [3], 
as well as in plant alkaloids such as loroquin (4) [4] and the recently characterized pomegranate alkaloid punicagranine (5) (Figure 1) [5]. The 2,3-dihydro- $1 \mathrm{H}$-pyrrolizine motif is also a structural component of potential drugs with a variety of pharmacological effects [6], including anticancer activity [7]. Relevant examples include (-)-ketorolac (6) [8], which has reached the market as a nonsteroidal anti-inflammatory drug [6], and licofelone (7) $[9,10]$, a promising co-drug for anticancer combination chemotherapy [7]. Related 5,6,7,8-tetrahydroindolizines such as CMV423 (8) [11], a lead compound for treating infections by human cytomegalovirus, and the natural products polygonatine A (9) [12] and procuramine (10) [13], have also attracted attention recently.

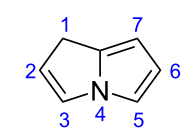

$1 H$-pyrrolizine (1)

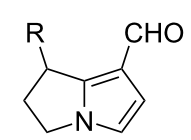

danaidal (2), $\mathrm{R}=\mathrm{H}$ hydroxydanaidal (3), $\mathrm{R}=\mathrm{OH}$

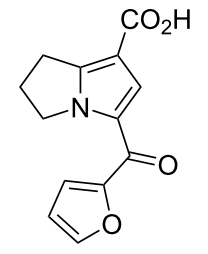

punicagranine (5) (-)-ketorolac (6)<smiles>NC(=O)c1c(Cl)c(-c2cccnc2)n2c1CCCC2</smiles><smiles>O=C1CCCn2c(CO)ccc21</smiles>

polygonatine $A(\mathbf{9})$<smiles>O=C(c1ccccc1)c1ccc2n1CC[C@@H]2C(=O)O</smiles>

CMV423 (8)

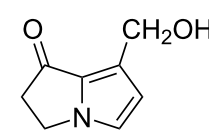

loroquin (4)<smiles>CC1(C)Cc2c(-c3ccccc3)c(-c3ccc(Cl)cc3)c(CC(=O)O)n2C1</smiles>

licofelone (7)

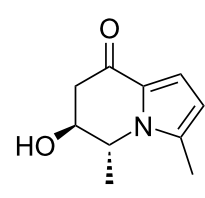

procuramine (10)
Figure 1: Examples of 2,3-dihydro-1H-pyrrolizines (1-7) and 5,6,7,8 tetrahydroindolizines (8-10).

Our continuing efforts to exploit enaminones as building blocks for the synthesis of alkaloids and other nitrogen-containing heterocycles have largely concentrated on targets containing indolizidine and quinolizidine backbones [14]. The pyrrolizidine motif has up to now eluded us other than when it forms part of the tricyclic 2,3-dihydro- $1 H$-pyrrolo[1,2- $a$ ]indole system [15], as in our route to aziridinomitosenes [16,17]. In the course of our attempts at the syntheses of aryl-bearing indolizidine alkaloids via $N$-phenacyl vinylogous amides such as 11, however, we fortuitously found substituted 2,3-dihydro$1 H$-pyrrolizines 12 as unexpected products when intermediates 11 were exposed to acidic conditions, including treatment with acetic acid or even during chromatography on silica gel
(Scheme 1) [18]. In these cyclizations the enaminone acts as an intramolecular nucleophile towards the phenacyl substituent, even though the nucleophilic character of the enamine component is expected to be suppressed by the "push-pull" effect arising from the electron-withdrawing carbonyl group [19-23]. The dual properties of enaminones as both nucleophiles and electrophiles have frequently been exploited in the synthesis of heterocyclic products, including pyrroles and related systems [22-28]. Nonetheless, encouraged by the ease of access to pyrrole-containing products of type $\mathbf{1 2}$ and their potential synthetic utility, we surmised that replacing the aroyl component of the $N$-phenacyl substituent by electrophilic groups such as esters, amides or nitriles might yield 2,3-dihydro- $1 H$-pyrrolizin6-ones $\mathbf{1 3}$ or their hydroxypyrrole tautomers 13'. Our findings with $N$-(ethoxycarbonylmethyl)enaminones $\mathbf{1 4}$ are described in this article.
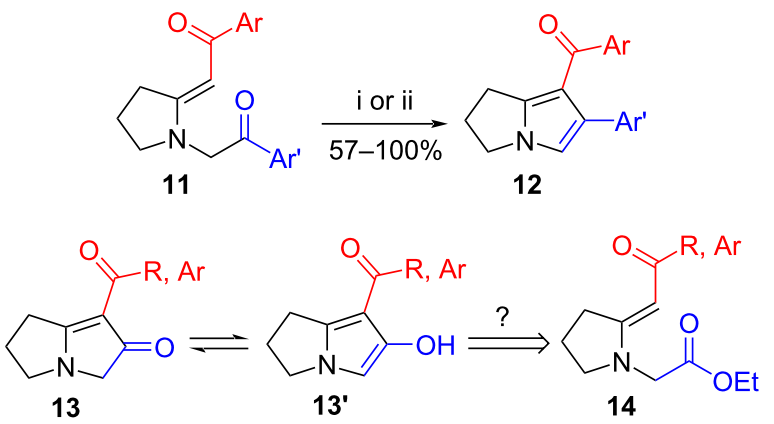

Scheme 1: Previous [18] and proposed routes to 2,3-dihydro- $1 \mathrm{H}$ pyrrolizines from enaminones. Reagents and conditions: (i) $\mathrm{AcOH}-\mathrm{MeOH}, \mathrm{rt}, 18-24 \mathrm{~h}$; (ii) $\mathrm{SiO}_{2}, 90^{\circ} \mathrm{C}, 1-2 \mathrm{~h}$.

\section{Results and Discussion}

The benzoyl-containing enaminone 15a $(\mathrm{Ar}=\mathrm{Ph})$ was selected as a model for investigating conditions for the cyclization. This compound was conveniently prepared by Eschenmoser sulfide contraction [29,30], as shown in Scheme 2. The route entailed initial alkylation of the anion of pyrrolidin-2-one (16) with ethyl bromoacetate to afford the known compound ethyl 2-(2-oxopyrrolidin-1-yl)acetate (17) [31-33] in 77\% yield. Thionation of 17 with Lawesson's reagent in toluene at $80{ }^{\circ} \mathrm{C}$ gave the thione $\mathbf{1 8}$ as a yellow oil (86\%). Reaction of $\mathbf{1 8}$ with phenacyl bromide in acetonitrile at ambient temperature to produce the putative S-alkylated salt was complete within 18 hours, after which treatment with triethyl phosphite and triethylamine rapidly completed the sulfide contraction, giving $(E)$-enaminone 15a in $92 \%$ yield after chromatographic purification. The geometry was inferred from its NOESY spectrum, which showed a weak but distinct correlation between the vinyl proton singlet ( $\delta$ 5.66) and the methylene group flanked by nitrogen and the ester ( $\delta$ 4.06). The $E$-geometry was also suggested by the chemical 

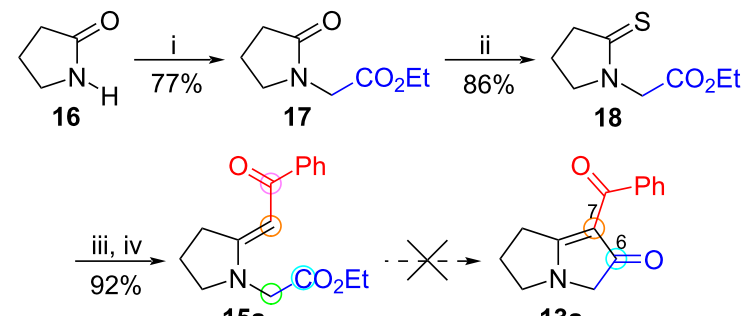

$$
\text { or } \begin{gathered}
\mathrm{vi} \\
93 \%
\end{gathered}
$$

$19 a$

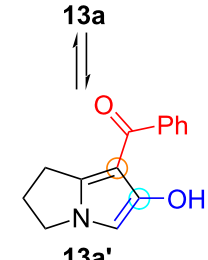

$13 a^{\prime}$

Scheme 2: Synthesis of pyrrolizine 19a from lactam 16 via enaminone 15a. Reagents and conditions: (i) $\mathrm{NaH}$, THF, rt, $2.3 \mathrm{~h}$, then $\mathrm{BrCH}_{2} \mathrm{CO}_{2} \mathrm{Et}$, rt, $16 \mathrm{~h}$; (ii) Lawesson's reagent, toluene, $80^{\circ} \mathrm{C}, 18 \mathrm{~h}$; (iii) $\mathrm{BrCH}_{2} \mathrm{COPh}, \mathrm{MeCN}$, rt, overnight; (iv) $\mathrm{P}(\mathrm{OEt})_{3}, \mathrm{NEt}_{3}, \mathrm{MeCN}$, rt, $18 \mathrm{~h}$; (v) $\mathrm{AcOH}$, microwaves ( $\left.150 \mathrm{~W}, 140{ }^{\circ} \mathrm{C}\right), 10 \mathrm{~min}$; (vi) $\mathrm{SiO}_{2}$, xylene, microwaves $\left(150 \mathrm{~W}, 150^{\circ} \mathrm{C}\right), 3.5 \mathrm{~min}$. shift of the hydrogen atoms at C-3 of the pyrrolidine ring ( $\delta$ 3.43), which showed anisotropic deshielding by the carbonyl group. In similar pyrrolidine-containing $(Z)$-enaminones these hydrogen atoms appear approximately $0.5-0.7 \mathrm{ppm}$ upfield (ca. $\delta$ 2.5-2.7) compared to the chemical shifts of related $(E)$-enaminones $[29,34]$.

In contrast to the corresponding $N$-phenacyl analogue $\mathbf{1 1}(\mathrm{Ar}=$ $\mathrm{Ar}^{\prime}=\mathrm{Ph}$ ), the ester-containing enaminone 15a proved to be completely stable during chromatography on silica gel or upon dissolution in acetic acid at room temperature (conditions under which we had observed cyclization of vinylogous amides 11 [18]), and spontaneous cyclization to the expected pyrrolizinone 13a or tautomer 13a' did not take place (Table 1, entry 1). More vigorous conditions were therefore investigated. Heating 15a in acetic acid $(150 \mathrm{~W})$ for 10 minutes at $140{ }^{\circ} \mathrm{C}$ produced a new product in $72 \%$ yield (Table 1 , entry 2 ). However, the isolated product was not the expected pyrrolizinone 13a/13a', but the 2,3-dihydro- $1 H$-pyrrolizine ester 19a. The expected signals for

\begin{tabular}{|c|c|c|c|c|c|}
\hline Entry & Solvent & Additive & Temp. $^{a}$ & Time & Yield of $19 a(\%)$ \\
\hline 1 & $\mathrm{CH}_{3} \mathrm{CO}_{2} \mathrm{H}$ & - & rt & $18 \mathrm{~h}$ & $-\mathrm{b}$ \\
\hline 2 & $\mathrm{CH}_{3} \mathrm{CO}_{2} \mathrm{H}$ & - & $140^{\circ} \mathrm{C}$ & $10 \mathrm{~min}$ & 72 \\
\hline 3 & $\mathrm{EtOH}$ & - & $100^{\circ} \mathrm{C}$ & $10 \mathrm{~min}$ & $-^{b}$ \\
\hline 4 & xylene & - & $150^{\circ} \mathrm{C}$ & $10 \mathrm{~min}$ & $-\mathrm{b}$ \\
\hline 5 & DMF & - & $150^{\circ} \mathrm{C}$ & $10 \mathrm{~min}$ & $-\mathrm{b}$ \\
\hline 6 & conc. $\mathrm{HCl}$ & - & $\mathrm{rt}$ & $10 \mathrm{~min}$ & $-^{c}$ \\
\hline 7 & conc. $\mathrm{HCl}$ & - & $\mathrm{rt}$ & $18 \mathrm{~h}$ & $-d$ \\
\hline 8 & conc. $\mathrm{HCl}$ & - & $50^{\circ} \mathrm{C}$ & $10 \mathrm{~min}$ & $-d$ \\
\hline 9 & $\mathrm{CF}_{3} \mathrm{CO}_{2} \mathrm{H}$ & - & $\mathrm{rt}$ & $18 \mathrm{~h}$ & $-d$ \\
\hline 10 & $\mathrm{MeSO}_{3} \mathrm{H}$ & - & $\mathrm{rt}$ & $10 \min$ & $-^{c}$ \\
\hline 11 & $\mathrm{MeSO}_{3} \mathrm{H}$ & - & $\mathrm{rt}$ & $18 \mathrm{~h}$ & $-d$ \\
\hline 12 & $\mathrm{MeSO}_{3} \mathrm{H}$ & - & $50^{\circ} \mathrm{C}$ & $10 \mathrm{~min}$ & $-d$ \\
\hline 13 & $\mathrm{BF}_{3} \cdot \mathrm{OEt}_{2}$ & - & $\mathrm{rt}$ & $18 \mathrm{~h}$ & $-d$ \\
\hline 14 & $\mathrm{EtOH}$ & $\mathrm{HCl}$ (cat.) & $\mathrm{rt}$ & $18 \mathrm{~h}$ & $-\mathrm{b}$ \\
\hline 15 & $\mathrm{EtOH}$ & $\mathrm{HCl}$ (cat.) & $100^{\circ} \mathrm{C}$ & $10 \min$ & $-d$ \\
\hline 16 & $\mathrm{CH}_{2} \mathrm{Cl}_{2}$ & $\mathrm{AlCl}_{3}$ & $\mathrm{rt}$ & $18 \mathrm{~h}$ & $-^{b}$ \\
\hline 17 & $\mathrm{CH}_{2} \mathrm{Cl}_{2}$ & $\mathrm{AlCl}_{3}$ & $50^{\circ} \mathrm{C}$ & $10 \min$ & $-d$ \\
\hline 18 & $\mathrm{CH}_{2} \mathrm{Cl}_{2}$ & $\mathrm{BF}_{3} \cdot \mathrm{OEt}_{2}$ & rt & $18 \mathrm{~h}$ & $-^{b}$ \\
\hline 19 & $\mathrm{CH}_{2} \mathrm{Cl}_{2}$ & $\mathrm{BF}_{3} \cdot \mathrm{OEt}_{2}$ & $50^{\circ} \mathrm{C}$ & $10 \min$ & $-^{d}$ \\
\hline 20 & $\mathrm{CH}_{2} \mathrm{Cl}_{2}$ & Amberlyst 15 & $\mathrm{rt}$ & $24 \mathrm{~h}$ & $-{ }^{c}$ \\
\hline 21 & $\mathrm{CH}_{2} \mathrm{Cl}_{2}$ & Amberlyst 15 & $50^{\circ} \mathrm{C}$ & $10 \min$ & $-^{c}$ \\
\hline 22 & xylene & Montmorillonite K10 & $\mathrm{rt}$ & $18 \mathrm{~h}$ & $-d$ \\
\hline 23 & xylene & Montmorillonite $\mathrm{K} 10$ & $150^{\circ} \mathrm{C}$ & $10 \min$ & 84 \\
\hline 24 & xylene & silica gel & rt & $18 \mathrm{~h}$ & $-\mathrm{b}$ \\
\hline 25 & toluene & silica gel & $140^{\circ} \mathrm{C}$ & $8 \min$ & 90 \\
\hline 26 & xylene & silica gel & $150{ }^{\circ} \mathrm{C}$ & $3.5 \min$ & 93 \\
\hline
\end{tabular}

Table 1: Optimization of the cyclization of enaminone 15a to pyrrolizine $19 \mathrm{a}$.

aMicrowave heating $(150 \mathrm{~W})$ in a capped tube. ${ }^{b}$ No reaction and no apparent decomposition. ${ }^{\mathrm{c}} \mathbf{1 5 a}$ was protonated, but regenerated on treatment with aq $\mathrm{NaHCO}_{3}$ (TLC). ${ }^{\mathrm{d}}$ Decomposition was observed. 
the ethyl ester were apparent in the ${ }^{1} \mathrm{H}$ NMR spectrum, the lone pyrrole hydrogen appeared as a singlet at $\delta 5.95$, and the ester carbonyl group occurred at $\delta 161.4$ in the ${ }^{13} \mathrm{C}$ NMR spectrum. In other words, the enaminone component did not act as a nucleophile towards the ester, as it did with the $N$-phenacylenaminones 11. Instead, it functioned as an electrophile at its carbonyl group by condensation with the methylene unit $\alpha$ to the ester, thereby forming the C5-C6 bond of the azabicyclic system instead of the C6-C7 bond.

A brief survey of alternative conditions for the cyclization revealed that the acidic conditions under which pyrrolizine formation took place were essential, although the nature of the acid proved to be critical (Table 1). Starting material was recovered unchanged when 15a was heated in capped tubes under microwave conditions [35-37] for 10 minutes in solvents such as ethanol $\left(100{ }^{\circ} \mathrm{C}\right)$, xylene $\left(150{ }^{\circ} \mathrm{C}\right)$ or $N, N$-dimethylformamide $\left(150{ }^{\circ} \mathrm{C}\right.$ ) (Table 1, entries 3-5). Dissolution in neat protic or Lewis acids (e.g., hydrochloric acid, trifluoroacetic acid, methanesulfonic acid, boron trifluoride etherate) resulted in decomposition if the reactions were left at room temperature overnight, or within ten minutes if the temperature was raised, even to $50{ }^{\circ} \mathrm{C}$ (Table 1 , entries 6-13). The enaminone appeared to be protonated at room temperature, presumably on the oxygen site in accordance with well-established precedents [38,39]; and after ten minutes it could be recovered after neutralization with aqueous sodium hydrogen carbonate (Table 1 , entries 6,10$)$. No apparent reaction occurred with dilute hydrochloric acid in ethanol (Table 1, entry 14) unless the solution was heated, in which case decomposition took place (Table 1, entry 15). Solutions of $\mathbf{1 5 a}$ in dichloromethane also decomposed rapidly when treated with aluminum trichloride or boron trifluoride at $50{ }^{\circ} \mathrm{C}$, although no reaction was apparent at room temperature even after 18 hours (Table 1, entries 16-19). When a solution of 15a in dichloromethane was treated with Amberlyst 15, an ion exchange resin with a strongly acidic sulfonic acid [40], it was rapidly adsorbed and presumably protonated, but it could be displaced from the resin upon treatment with aqueous sodium hydrogen carbonate (Table 1, entries 20 and 21). More interestingly, microwave heating at $150{ }^{\circ} \mathrm{C}$ for no more than 10 minutes of a solution of 15a in xylene with montmorillonite $\mathrm{K} 10$, an acidic layered aluminosilicate clay often used as a catalyst in microwave-assisted organic synthesis [41-44], also afforded the pyrrolizine 19a in a good yield of $84 \%$, although prolonged exposure even at ambient temperature led to decomposition (Table 1, entries 22 and 23). However, the most successful microwave-assisted reactions took place with the somewhat less acidic silica gel (200-400 mesh) as the promotor [45]. Mixing a solution of the enaminone in toluene or xylene with silica gel prior to microwave heating at $140-150{ }^{\circ} \mathrm{C}$ with moderate stirring for just a few minutes rapidly produced the product 19a which, after evaporation of the solvent, was cleanly eluted from the adsorbent by chromatography on silica gel with ethyl acetate-hexane mixtures. Yields in toluene or xylene were typically around $90 \%$ (Table 1, entries 25 and 26). Although most reported microwave-promoted organic reactions on solid supports are performed without additional solvent $[46,47]$, the combination of a nonpolar solvent with a polar heterogeneous catalyst can be effective as a consequence of the solid selectively absorbing the microwave energy and facilitating reaction at its surface, while the nonpolar solvent absorbs relatively little microwave energy and remains at a milder temperature.

The weakly acidic conditions appear to serve several functions. Firstly, the $E$-geometry of reactant $\mathbf{1 5 a}$ is obviously incorrect for the cyclization, which requires the nucleophilic methylene adjacent to the ester to approach close enough to the electrophilic carbonyl group of the enaminone for the intramolecular condensation to occur. It is possible that acid-induced isomerization to the $Z$-isomer $(Z)-\mathbf{1 5 a}$, which is required for cyclization, proceeds through the protonated intermediate $\mathbf{2 0}$, in which the weakened double bond permits configurational equilibration between the geometric isomers [20] (Scheme 3). Alternatively, a purely thermal $E$-to- $Z$ isomerization of the enaminone prior to acid-promoted cyclization cannot be ruled out, since conjugation in the push-pull system should weaken the $\mathrm{C}=\mathrm{C}$ bond and lower its rotational barrier [20]. Similar enaminone isomerizations have been detected even at room temperature [48]. If thermal isomerization indeed takes place, then one could envisage rotation about the $\mathrm{C}-\mathrm{C}$ single bond in the zwitterionic mesomer of (E)-15a (i.e., 15a') leading to the rotamer 15a", and hence (Z)-15a. It must be noted, however, that we never managed to obtain direct evidence, whether by TLC or NMR spectroscopy, for the short-lived intermediate $(Z)$-15a. Nonetheless, use of the weaker acids seems to be crucial, since with strong acids the protonation to $\mathbf{2 0}$ appears not to be reversible, and direct cyclization of 20 to 19a cannot be occurring (cf. Table 1, entries 6-21). Secondly, the acid is also likely to facilitate enolization of the ester such that 5-exo-trig interactions of both the enol nucleophile and the ketone in the transient intermediate $\mathbf{2 1}$ bring about formation of the new five-membered ring intermediate 22. Finally, acid-induced dehydration of $\mathbf{2 2}$ completes the formation of the pyrrole ring, resulting in conversion into the dihydropyrrolizine 19a. This enaminone-based method for constructing a pyrrole ring is similar to that in our reported routes to lamellarin alkaloids, in which $\mathrm{N}$-alkylation of $(Z)$-configured 3,4-dihydroisoquinoline-derived enaminones with ethyl bromoacetate under either conventional $[49,50]$ or microwave [51] heating conditions yielded pyrrolo[2,1- $a$ ] isoquinoline products. A somewhat comparable cyclization of $N$-benzylenaminones has been reported under superbasic conditions [52], 
while base-induced pyrrole formation from $N$-(ethoxycarbonylmethyl)enamino esters (vinylogous urethanes) and the corresponding nitriles (vinylogous cyanamides) has also been described [53]. A similar base-induced cyclization of $N$-(alkoxycarbonylmethyl)-7-formylindoles to give pyrrolo[3,2,1$h i$ ]indoles is also of interest [54]. Acid-induced cyclization akin to ours, and also assuming an in situ $E$ to $Z$ isomerization under the reaction conditions, was reported as recently as 2018 [55]. More interestingly, conventional heating in acetic acid of an enaminone bearing a phenacylsulfanyl substituent adjacent to nitrogen on the $\mathrm{C}=\mathrm{C}$ bond produced ethyl pyrrolo[2,1-b]thiazole-5-carboxylates in moderate yield, while the corresponding microwave-assisted reaction in the same solvent gave high yields of pyrrolo[2,1-b]thiazol-6-ones [56]. The former results from reaction between the $\alpha$-methylene position of the ester and the electrophilic carbonyl component of the enaminone, while the latter arises from nucleophilic attack of the enaminone at the ester's carbonyl group. This appears to be a rare example of a change in reaction conditions swinging the outcome from one mode of enaminone reactivity to the other.

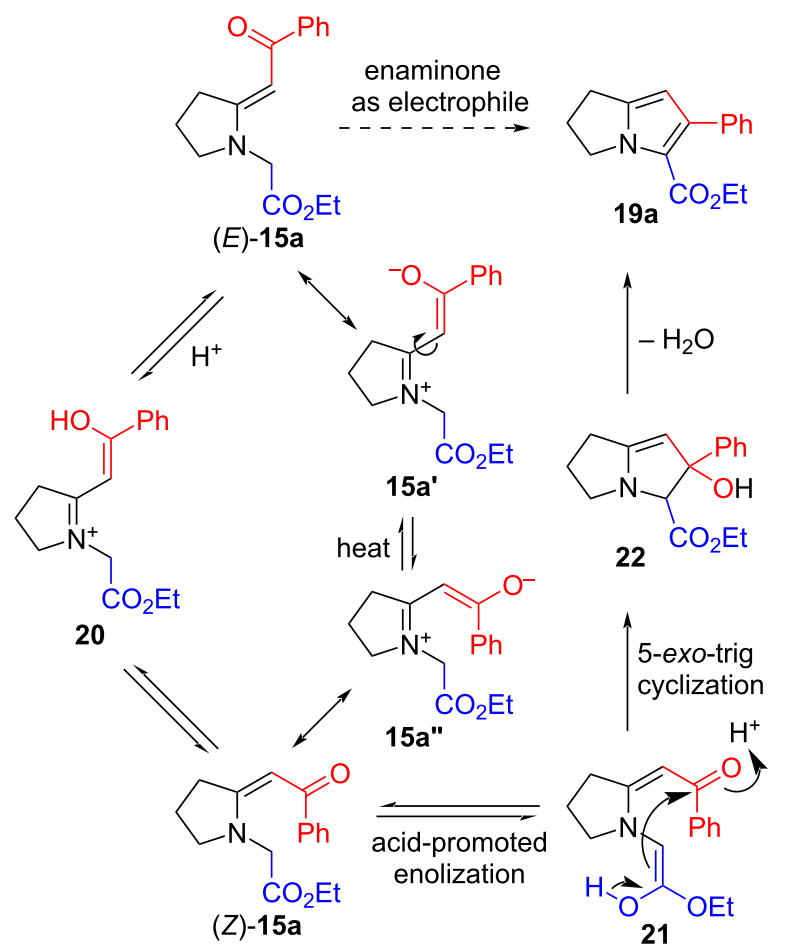

Scheme 3: Proposed mechanism for the formation of pyrrolizidine 19a from enaminone $(E)-15 a$

Following this optimized method, we undertook the synthesis of a range of enaminones $\mathbf{1 5}$ bearing a variety of aroyl and heteroaroyl substituents as well as tert-butyl as precursors for the silica gel-mediated cyclization reaction to form pyrrolizine products. The bromomethyl ketones required for the initial sulfide contraction were either purchased from commercial suppliers or prepared from the corresponding methyl ketones by reported procedures [57-65]. Results are summarized in Table 2. Triphenylphosphine and triethyl phosphite could be used interchangeably in the sulfur extrusion step. However, in most cases the co-elution of enaminones 15 with phosphorusderived byproducts during chromatographic purification was unavoidable, and multiple chromatographic separations reduced the isolated yields. Such contamination with phosphorus-containing byproducts is a well-known problem in Eschenmoser condensations [30]. With particularly difficult separations we simply subjected the impure intermediates (for most of which characteristic ${ }^{1} \mathrm{H}$ or ${ }^{13} \mathrm{C}$ NMR spectroscopic signals could be observed, and suitable HRMS values could be measured; see Supporting Information File 1) to the optimized cyclization reaction conditions, since the contaminants did not inhibit pyrrolizine formation. Chromatographic purification of products 19 thereafter proved to be easier as they are less polar than the enaminones, and could generally be separated from other byproducts. In these cases, overall isolated yields of the dihydropyrrolizines $\mathbf{1 9}$ are reported over the two steps.

The approximate time for completion of the cyclization of enaminones 15 to pyrrolizines 19 was determined by TLC monitoring of the reaction mixture after successive time intervals. A fairly accurate estimate of the reaction time as a function of the changing acyl substituent could thus be obtained to within 30 seconds. As can be seen from Table 2, we observed a distinct rate dependence on both the size and the electronic properties of aroyl substituents. In general, electron-withdrawing substituents produced an increase in reaction rate relative to the unsubstituted parent 15a, while electron-donating substituents on the para-position of the aromatic ring tended to slow down the reaction (Table 2, entries 1-7). This is to be expected as a consequence of the mesomeric effects of the aryl substituents on the electrophilicity of the carbonyl group. Substituents in the meta-position, whether electron-withdrawing or electron-donating (Table 2, entries 8 and 9), had a negligible electronic influence on the carbonyl group, and the time in which cyclization was completed was essentially the same as for the unsubstituted phenyl precursor 15a. For the 3,4-dimethoxyphenyl substrate $\mathbf{1 5} \mathbf{j}$ containing both meta- and para-substituents, only the latter affected the rate, and the cyclization time was the same as for the 4-methoxyphenyl system $\mathbf{1 5 g}$ (Table 2, entry 10 vs 7).

The outcome was more complex with ortho-substituents on the aromatic ring, since both steric and electronic effects are likely to operate. When chemically labile groups are present, decomposition of the putative pyrrolizine product appears to be faster 
Table 2: Preparation of enaminones $15 a-y^{a}$, and cyclization to dihydropyrrolizines $19 a-y^{b}$.

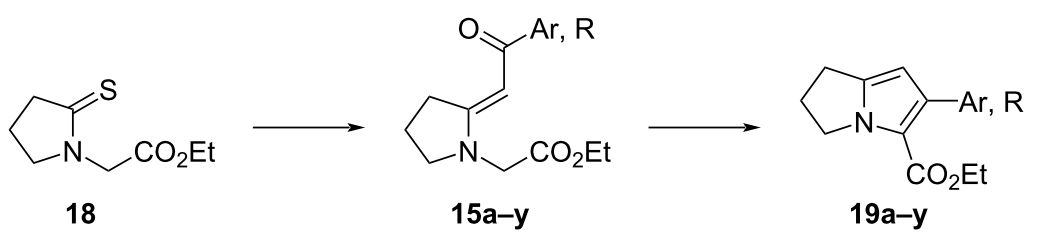

\begin{tabular}{|c|c|c|c|c|c|}
\hline Entry & Compound 15/19 & Ar or $\mathrm{R}$ & Yield of 15 (\%) & $\begin{array}{l}\text { Cyclization time } \\
\text { (min) }\end{array}$ & Yield of $19(\%)$ \\
\hline 1 & a & $\mathrm{C}_{6} \mathrm{H}_{5}$ & $92^{\mathrm{C}}$ & 3.5 & 93 \\
\hline 2 & b & $4-\mathrm{NO}_{2}-\mathrm{C}_{6} \mathrm{H}_{4}$ & $99^{c}$ & 0.5 & 78 \\
\hline 3 & c & $4-\mathrm{CN}-\mathrm{C}_{6} \mathrm{H}_{4}$ & $92^{\mathrm{C}}$ & 3 & 92 \\
\hline 4 & d & $4-\mathrm{F}-\mathrm{C}_{6} \mathrm{H}_{4}$ & $90^{d}$ & 5 & 98 \\
\hline 5 & e & $4-\mathrm{Br}-\mathrm{C}_{6} \mathrm{H}_{4}$ & $93^{c}$ & 4.5 & 98 \\
\hline 6 & $f$ & 4-Me- $\mathrm{C}_{6} \mathrm{H}_{4}$ & $82^{c}$ & 4.5 & 89 \\
\hline 7 & g & 4- $\mathrm{MeO}-\mathrm{C}_{6} \mathrm{H}_{4}$ & $84^{c}$ & 5 & 96 \\
\hline 8 & h & $3-\mathrm{NO}_{2}-\mathrm{C}_{6} \mathrm{H}_{4}$ & $99^{c}$ & 3.5 & 77 \\
\hline 9 & $\mathbf{i}$ & $3-\mathrm{MeO}-\mathrm{C}_{6} \mathrm{H}_{4}$ & d, e & 3.5 & $81^{f}$ \\
\hline 10 & j & $3,4-(\mathrm{MeO})_{2}-\mathrm{C}_{6} \mathrm{H}_{3}$ & $\mathrm{~d}, \mathrm{e}$ & 5 & $89^{f}$ \\
\hline 11 & $\mathbf{k}$ & $2-\mathrm{NO}_{2}-\mathrm{C}_{6} \mathrm{H}_{4}$ & $87^{c}$ & 0.5 & $0^{g}$ \\
\hline 12 & I & $2-\mathrm{I}_{-} \mathrm{C}_{6} \mathrm{H}_{4}$ & $93^{c}$ & 10 & $0^{9}$ \\
\hline 13 & $\mathbf{m}$ & $2-\mathrm{Br}-\mathrm{C}_{6} \mathrm{H}_{4}$ & $\mathrm{c}, \mathrm{e}$ & 9 & $46^{f, g}$ \\
\hline 14 & $\mathbf{n}$ & $2-\mathrm{Br}-4,5-(\mathrm{MeO})_{2}-\mathrm{C}_{6} \mathrm{H}_{2}$ & $93^{c}$ & 9 & $35^{9}$ \\
\hline 15 & 0 & $2-\mathrm{Cl}-\mathrm{C}_{6} \mathrm{H}_{4}$ & $92^{\mathrm{C}}$ & 9 & 92 \\
\hline 16 & $\mathbf{p}$ & 2-MeO- $\mathrm{C}_{6} \mathrm{H}_{4}$ & $\mathrm{c}, \mathrm{e}$ & 9 & $82^{f}$ \\
\hline 17 & $q$ & $2,5-(\mathrm{MeO})_{2}-\mathrm{C}_{6} \mathrm{H}_{3}$ & $d, e$ & 7 & $82^{f}$ \\
\hline 18 & $r$ & $2-\mathrm{F}-\mathrm{C}_{6} \mathrm{H}_{4}$ & $d, e$ & 1.5 & $99^{f}$ \\
\hline 19 & s & naphthalen-1-yl & $\mathrm{d}, \mathrm{e}$ & 17 & $81^{f}$ \\
\hline 20 & $\mathbf{t}$ & styryl & $88^{c}$ & 0.5 & 82 \\
\hline 21 & $\mathbf{u}$ & furan-2-yl & $93^{d}$ & 5.5 & 100 \\
\hline 22 & $\mathbf{v}$ & thien-2-yl & $d, e$ & 4.5 & $99^{f}$ \\
\hline 23 & w & benzofuran-2-yl & $93^{d}$ & 2.5 & 96 \\
\hline 24 & $\mathbf{x}$ & $N$-tosylindol-3-yl & $88^{d}$ & 2 & 92 \\
\hline 25 & y & $\mathrm{C}\left(\mathrm{CH}_{3}\right)_{3}$ & $57^{d}$ & 19 & 81 \\
\hline
\end{tabular}

a18 (1 equiv), bromomethyl ketone (1.2 equiv), $\mathrm{MeCN}$, rt, $18 \mathrm{~h}$; then add $\mathrm{PPh}_{3}$ or $\mathrm{P}(\mathrm{OEt})_{3}, \mathrm{NEt}_{3}$, rt. b $\mathrm{SiO}_{2}(500 \mathrm{wt} \%), \mathrm{xylene}, \mathrm{MW}(180 \mathrm{~W})$, internal

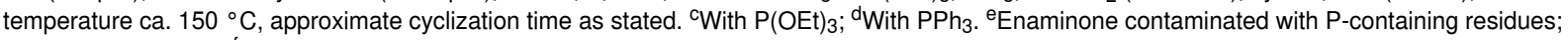
yield not determined. ${ }^{f}$ Yield calculated over two steps. ${ }^{9}$ Significant decomposition was observed.

than the rate of cyclization of the enaminone. In particular, decomposition occurred during the attempted cyclization of the 2-nitrophenyl- and 2-iodophenylenaminones $15 \mathbf{k}$ and $15 \mathrm{l}$ even before all of the precursor had been consumed. In the 2-nitro case decomposition was noted within 30 seconds, while for the 2-iodo compound complete decomposition took place within 10 minutes (Table 2, entries 11 and 12). Less problematic were the ortho-bromo examples (Table 2, entries 13 and 14), although the cyclizations proceeded with significantly reduced yields and decomposition was still evident. 2-Bromophenylenaminone $15 \mathrm{~m}$ gave a disappointing yield of $46 \%$ for $19 \mathrm{~m}$ after a comparatively long reaction time of nine minutes, while the more electron-rich 2-bromo-4,5-dimethoxy analogue 15n gave an even lower yield of $35 \%$ in the same reaction time. However, the 2-chlorophenyl, 2-methoxyphenyl and 2,5dimethoxyphenylenaminones 150-q proved to be well behaved, and gave excellent yields of pyrrolizines 19o-q (82-92\%), although in relatively long times (7-9 minutes). Perhaps most surprising was the speed and efficiency of cyclization of the 2-fluorophenyl enaminone $\mathbf{1 5 r}$, which was prepared in situ prior to cyclization. The pyrrolizine 19r was obtained within 90 seconds of microwave heating, and in $99 \%$ yield over the 
two steps. The rapidity of the condensation probably reflects both the inductive electron-withdrawing effect of fluorine and the minimal steric constraints offered by this small substituent Other examples that illustrate the likely influence of steric factors are provided by the naphthalen-1-yl- and styrylenaminones $15 \mathrm{~s}$ and $15 \mathrm{t}$, cyclization of which required 17 minutes and 30 seconds, respectively. The bulkiness of the former hinders the approach of the nucleophile to the carbonyl site, while in the latter case insertion of the vinyl unit between the carbonyl and the aryl ring makes the electrophilic site in the enaminone significantly less crowded.

Cyclization of enaminones bearing heteroaromatic substituents proceeded very well (Table 2, entries 21-24). Reaction of the electron-rich furyl- and thiophenyl-bearing precursors $15 \mathbf{u}$ and $\mathbf{1 5} \mathbf{v}$ was slower than with the phenyl parent 15a, once again reflecting the rate-retarding effect of the electron-donating rings. However, cyclization of both the benzo-fused heterocyclic systems $\mathbf{1 5 w}$ and $\mathbf{1 5 x}$ was surprisingly fast despite their greater steric bulk. The only successful pyrrolizine formation with an alkyl rather than an aryl substituent was with the tertbutylenaminone $\mathbf{1 5 y}$, which was itself prepared from thiolactam 18 and bromopinacolone in a rather poor yield of $57 \%$. The cyclization afforded pyrrolizine 19y in $81 \%$ yield, albeit in a markedly slow time of 19 minutes. Both the electron-donating nature and the size of this alkyl group probably slow down the reaction. We were unfortunately not successful with other nonaromatic substituents, including trifluoromethyl and ethoxycarbonyl groups, since the initial formation of the requisite enaminones (from $\mathbf{1 8}$ and 3-bromo-1,1,1-trifluoropropan-2-one or ethyl bromopyruvate, respectively) failed. Following up on reactions with these and other synthetically intriguing substituents will require a different method for making the necessary enaminones.

Our success with the microwave-assisted synthesis of 2,3dihydro- $1 H$-pyrrolizines from pyrrolidine-based enaminones suggested that the technique might also be suitable for preparing 5,6,7,8-tetrahydroindolizine analogues from the corresponding piperidine systems. In a preliminary investigation we prepared three such enaminones by the route shown in Scheme 4 Alkylation of piperidin-2-one (23) with ethyl bromoacetate followed by treatment of the resulting lactam $[66,67]$ with Lawesson's reagent in toluene at $80{ }^{\circ} \mathrm{C}$ gave the thione $\mathbf{2 4}$ in $83 \%$ overall yield. Reaction of $\mathbf{2 4}$ with phenacyl bromide and its 4-methoxy and 4-nitro congeners in acetonitrile, followed by sulfide contraction of the resulting thioiminium ether salts with triethylamine and triethyl phosphite, afforded the $(E)$-enaminones 25a-c in yields of $86-89 \%$. The $E$-geometry of 25a was again confirmed by NOESY NMR spectroscopy, which showed an interaction between the vinyl hydrogen $(\delta 5.55)$ and the methylene unit adjacent to the ester ( $\delta 3.96)$. The through-space anisotropic deshielding of C-3 in the ring ( $\delta 3.32$ ) by the carbonyl group also supported the assignment of the geometry.

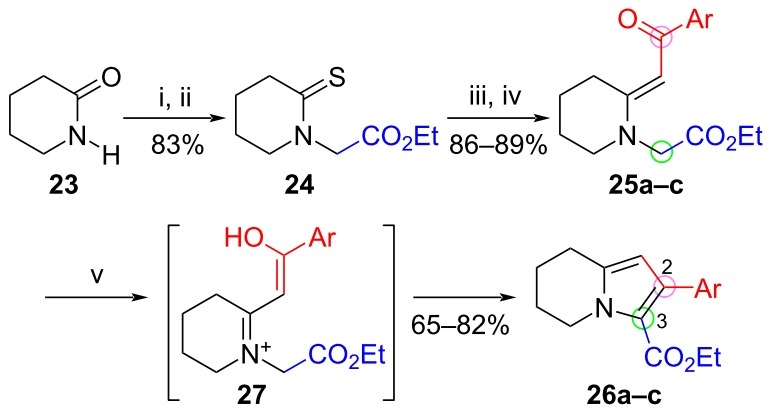

a, $\mathrm{Ar}=\mathrm{Ph} ; \mathrm{b}, \mathrm{Ar}=\mathrm{C}_{6} \mathrm{H}_{4}-4-\mathrm{OMe} ; \mathrm{c}, \mathrm{Ar}=\mathrm{C}_{6} \mathrm{H}_{4}-4-\mathrm{NO}_{2}$

Scheme 4: Synthesis of tetrahydroindolizines 26a-c from lactam 23 via enaminones 25a-c. Reagents and conditions: (i) $\mathrm{NaH}, \mathrm{THF}, \mathrm{rt}$, $2.3 \mathrm{~h}$, then $\mathrm{BrCH}_{2} \mathrm{CO}_{2} \mathrm{Et}, 0^{\circ} \mathrm{C}-\mathrm{rt}, 16 \mathrm{~h}$; (ii) Lawesson's reagent, $\mathrm{PhMe}$ $80^{\circ} \mathrm{C}, 18 \mathrm{~h}$; (iii) $\mathrm{BrCH}_{2} \mathrm{COAr}, \mathrm{MeCN}$, rt, overnight; (iv) $\mathrm{P}(\mathrm{OEt})_{3}, \mathrm{NEt}_{3}$, $\mathrm{MeCN}, \mathrm{rt}, 18 \mathrm{~h}$; (v) $\mathrm{SiO}_{2}$, EtOH, microwaves (50 W, $\left.100^{\circ} \mathrm{C}\right), 1-3 \mathrm{~h}$.

Microwave heating of intermediate 25a with silica gel in xylene under the cyclization conditions optimized for the formation of dihydropyrrolizines indeed produced the tetrahydroindolizine 26a, but in an extremely disappointing yield of less than $30 \%$. Significant decomposition was noted even when the temperature was reduced. From some exploratory TLC studies it appeared that, even in acetic acid at room temperature, protonation of 25a was virtually instantaneous and irreversible, as evinced by the formation of a baseline spot for the acetate salt. Since the analogous five-membered enaminones $\mathbf{1 5}$ form an obvious baseline salt spot only with strong protic acids but not with acetic acid, it appears that protonation of the pyrrolidinebased enaminones with this weak acid must be readily reversible. Thus the critical isomerization equilibrium postulated to be essential for pyrrolizine formation (see Scheme 3) appears not to operate to any appreciable extent with the six-membered analogues, which readily lose the exocyclic double bond to give the iminium system 27 upon essentially irreversible protonation. Is this perhaps another example of the lower reactivity and greater relative stability of double bonds exo- to five-membered rings when compared with their six-membered counterparts, as hypothesized by H. C. Brown nearly seven decades ago $[68,69]$ ? In Brown's own cautiously considered words, "Reactions which involve the formation or retention of an exo double bond in a 5-ring derivative will be favored over corresponding reactions which involve the formation or retention of an exo double bond in a 6-ring derivative. Reactions which involve the loss of an exo double bond will be favored in the 6-ring as compared to the corresponding 5-ring derivative" [69]. 
Since the presence of a proton donor even as weak as acetic acid was deleterious for tetrahydroindolizine formation from the piperidine-containing enaminone, we speculated that a simple polar protic solvent might be sufficiently "acidic" for the necessary $E / Z$ equilibration and cyclization of $\mathbf{2 5 a}$, even though this solvent was unsuitable for the cyclization of the pyrrolidine enaminones (cf. Table 1, entry 3 ). We were pleased to find that heating a solution of $25 \mathbf{a}$ in ethanol at $100{ }^{\circ} \mathrm{C}$ in a capped microwave tube, but at a much lower power setting $(50 \mathrm{~W})$, produced the desired product $\mathbf{2 6 a}$ in $82 \%$ yield with little obvious decomposition (Scheme 4). However, the reaction required four hours for the complete consumption of the enaminone. Interestingly, adding silica gel to the reaction mixture shortened the reaction time to 90 minutes. Replacing ethanol with xylene or the aprotic dipolar solvent DMF in the absence of silica gel failed to provide any trace of $\mathbf{2 6 a}$, proving that cyclization was not simply a thermally induced reaction, and supporting our premise that a unique protic solvent effect is crucial for facilitating this specific cyclization process.

We extended the successful reaction to the 4-methoxyphenyland 4-nitrophenylenaminones $\mathbf{2 5 b}$ and $\mathbf{2 5}$ c, which afforded tetrahydroindolizines $\mathbf{2 6 b}(74 \%)$ and $26 \mathbf{c}$ (65\%). The reaction times were 1 and 3 hours, respectively. Unexpectedly, the electronic rate dependence that was observed for the five-membered ring enaminones (where electron-withdrawing substituents caused faster cyclization) was reversed for these six-membered systems. At this stage we have too few examples to ascertain whether this is a genuine effect for the six-membered enaminones, and it would be premature to draw inferences about the detailed course of the reaction. It nevertheless suggests that there might be subtle mechanistic differences at work for the two families of enaminones, and further investigations are warranted.

Finally, in view of our interest in the synthesis of natural products possessing fully substituted pyrrole rings (e.g., the lamellarin alkaloids [50-52,70]), we also demonstrated that dihydropyrrolizines such as 19a could easily be functionalized on the unsubstituted pyrrole position (Scheme 5). This site was readily brominated with $\mathrm{N}$-bromosuccinimide in $\mathrm{N}, \mathrm{N}$-dimethylformamide [71] to afford ethyl 7-bromo-6-phenyl-2,3-dihydro$1 H$-pyrrolizine-5-carboxylate (28) in $83 \%$ yield. Palladium( $(0)$ catalyzed Suzuki-Miyaura coupling of $\mathbf{2 8}$ with phenylboronic acid efficiently yielded ethyl 6,7-diphenyl-2,3-dihydro- $1 H$ pyrrolizine-5-carboxylate (29) (82\%).

\section{Conclusion}

A variety of $N$-(ethoxycarbonylmethyl) vinylogous amides prepared in three steps from pyrrolidin-2-one (16) or piperidin-2one (23) underwent cyclization to yield 2,3-dihydro- $1 H$ -

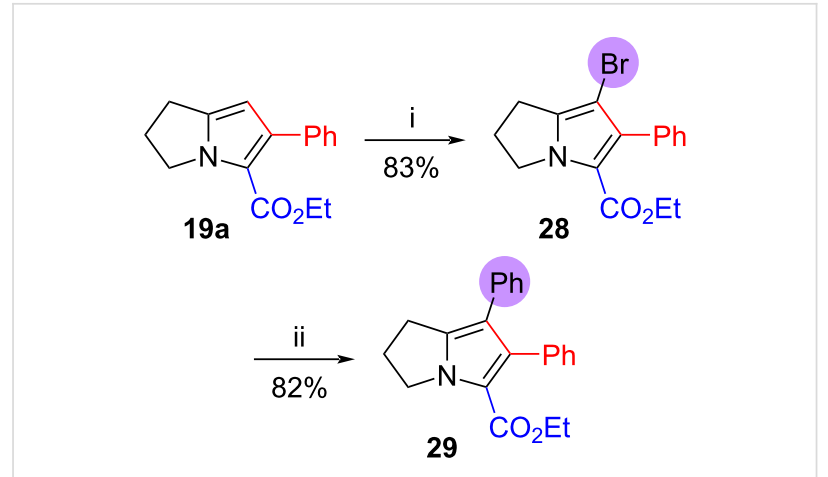

Scheme 5: Further functionalization of dihydropyrrolizine 19a Reagents and conditions: (i) NBS, DMF, $0{ }^{\circ} \mathrm{C}, 1 \mathrm{~h}$, then rt, $18 \mathrm{~h}$; (ii) $\mathrm{PhB}(\mathrm{OH})_{2}, \mathrm{Pd}\left(\mathrm{PPh}_{3}\right)_{4}$ (cat.), $\mathrm{Na}_{2} \mathrm{CO}_{3}$, DMF, reflux, $20 \mathrm{~h}$.

pyrrolizines 19 or 5,6,7,8-tetrahydroindolizines 26, respectively, when subjected to microwave heating with silica gel in suitable solvents. The enaminone acted as an electrophile in these cyclization reactions rather than as a nucleophile, as had previously been found with $N$-phenacyl analogues [18]. The formation of products 19 occurred within minutes at $150{ }^{\circ} \mathrm{C}$ in xylene, while formation of products 26 occurred in ethanol at $100{ }^{\circ} \mathrm{C}$ in a few hours. Yields were usually above $75 \%$ in both cases. Noteworthy features of the cyclization are that the reaction conditions are comparatively 'green', the products possess a rather uncommon biaryl axis with a pyrrole ring as one of the components, the pyrrole ring itself is created in an unusual manner, and further functionalization of the pyrrole ring is possible. Since both classes of azabicyclic product are well represented in compounds of pharmaceutical interest as well as in natural products, there is considerable synthetic potential in the transformation. Application of the methods described herein to the synthesis of lamellarin alkaloid analogues will be reported in due course.

\section{Supporting Information}

\section{Supporting Information File 1}

Experimental details for the synthesis and characterization of all compounds, and copies of ${ }^{1} \mathrm{H}$ NMR and ${ }^{13} \mathrm{C}$ NMR spectra.

[https://www.beilstein-journals.org/bjoc/content/ supplementary/1860-5397-17-170-S1.pdf]

\section{Funding}

The authors thank the University of the Witwatersrand and the South African National Research Foundation (NRF; grant numbers 85964, 93447 and 105839) for providing running expenses and student bursaries. 


\section{ORCID ${ }^{\circledR}$ iDs}

Robin Klintworth - https://orcid.org/0000-0003-1413-917X Stefania M. Scalzullo - https://orcid.org/0000-0002-5717-3952 Charles B. de Koning - https://orcid.org/0000-0003-4525-5130 Willem A. L. van Otterlo - https://orcid.org/0000-0002-3300-6463 Joseph P. Michael - https://orcid.org/0000-0002-2307-8068

\section{References}

1. Tamariz, J.; Burgueño-Tapia, E.; Vázquez, M. A.; Delgado, F. Pyrrolizidine Alkaloids. In The Alkaloids. Chemistry and Biology; Knölker, H.-J., Ed.; Academic Press: Cambridge, MA, USA, 2018; Vol. 80, pp 1-314. doi:10.1016/bs.alkal.2018.03.001

2. Robertson, J.; Stevens, K. Nat. Prod. Rep. 2017, 34, 62-89. doi:10.1039/c5np00076a

And earlier reviews in this series.

3. Komae, H.; Nishi, A.; Tanaka, T.; Hayashi, N.; Wesou, C.; Kuwahara, Y. Biochem. Syst. Ecol. 1982, 10, 181-183. doi:10.1016/0305-1978(82)90026-6

4. del Castillo, B.; de Aguirre, A. G. E.; Bretón, J. L.; González, A. G.; Trujillo, J. Tetrahedron Lett. 1970, 11, 1219-1220. doi:10.1016/s0040-4039(01)91592-8

5. Sun, H.-y.; Ma, N.; Pan, T.; Du, C.-I.; Sun, J.-Y. Tetrahedron Lett. 2019 60, 1231-1233. doi:10.1016/j.tetlet.2019.03.056

6. Gouda, A. M.; Abdelazeem, A. H. Eur. J. Med. Chem. 2016, 114, 257-292. doi:10.1016/j.ejmech.2016.01.055

7. Gouda, A. M.; Abdelazeem, A. H.; Omar, H. A.; Abdalla, A. N.; Abourehab, M. A. S.; Ali, H. I. Bioorg. Med. Chem. 2017, 25, 5637-5651. doi:10.1016/j.bmc.2017.08.039

8. Rooks, W. H., II; Tomolonis, A. J.; Maloney, P. J.; Wallach, M. B.; Schuler, M. E. Agents Actions 1982, 12, 684-690. doi:10.1007/bf01965079

9. Laufer, S. Inflammopharmacology 2001, 9, 101-112. doi:10.1163/156856001300248371

10. Kulkarni, S. K.; Pal Singh, V. P. Curr. Top. Med. Chem. 2007, 7, 251-263. doi:10.2174/156802607779941305

11. Snoeck, R.; Andrei, G.; Bodaghi, B.; Lagneaux, L.; Daelemans, D.; de Clercq, E.; Neyts, J.; Schols, D.; Naesens, L.; Michelson, S.; Bron, D.; Otto, M. J.; Bousseau, A.; Nemecek, C.; Roy, C. Antiviral Res. 2002, 55, 413-424. doi:10.1016/s0166-3542(02)00074-8

12. Sun, L.-R.; Li, X.; Wang, S.-X. J. Asian Nat. Prod. Res. 2005, 7, 127-130. doi:10.1080/10286020310001625157

13. Han, W. B.; Zhang, A. H.; Deng, X. Z.; Lei, X.; Tan, R. X. Org. Lett. 2016, 18, 1816-1819. doi:10.1021/acs.orglett.6b00549

14. Michael, J. P.; de Koning, C. B.; Gravestock, D.; Hosken, G. D.; Howard, A. S.; Jungmann, C. M.; Krause, R. W. M.; Parsons, A. S.; Pelly, S. C.; Stanbury, T. V. Pure Appl. Chem. 1999, 71, 979-988. doi:10.1351/pac199971060979

15. Michael, J. P.; Chang, S.-F.; Wilson, C. Tetrahedron Lett. 1993, 34, 8365-8368. doi:10.1016/s0040-4039(00)61432-6

16. Michael, J. P.; de Koning, C. B.; Petersen, R. L.; Stanbury, T. V. Tetrahedron Lett. 2001, 42, 7513-7516. doi:10.1016/s0040-4039(01)01597-0

17. Michael, J.; de Koning, C.; Mudzunga, T.; Petersen, R. Synlett 2006, 3284-3288. doi:10.1055/s-2006-951532

18. Morgans, G. L.; Fernandes, M. A.; van Otterlo, W. A. L.; Michael, J. P. ARKIVOC 2020, No. iii, 4-23. doi:10.24820/ark.5550190.p011.221

19. Greenhill, J. V. Chem. Soc. Rev. 1977, 6, 277-294. doi:10.1039/cs9770600277
20. Sandström, J. Static and dynamic stereochemistry of acceptor-substituted enamines. In The Chemistry of Enamines; Rappoport,, Z., Ed.; John Wiley \& Sons Ltd: Chichester, UK, 1994; pp 405-436. doi:10.1002/0470024763.ch6 and references cited therein.

21. Chattopadhyay, A. K.; Hanessian, S. Chem. Commun. 2015, 51 16437-16449. doi:10.1039/c5cc05891k

22. Stanovnik, B.; Svete, J. Chem. Rev. 2004, 104, 2433-2480. doi:10.1021/cr020093y

23. Dar'in, D. V.; Lobanov, P. S. Russ. Chem. Rev. 2015, 84, 601-633. doi: $10.1070 /$ rcr4528

24. Negri, G.; Kascheres, C.; Kascheres, A. J. J. Heterocycl. Chem. 2004, 41, 461-491. doi:10.1002/jhet.5570410402

25. Cheng, Y.; Huang, Z.-T.; Wang, M.-X. Curr. Org. Chem. 2004, 8 , 325-351. doi:10.2174/1385272043485936

26. Chattopadhyay, A. K.; Hanessian, S. Chem. Commun. 2015, 51, 16450-16467. doi:10.1039/c5cc05892a

27. Arshadi, S.; Vessally, E.; Edjlali, L.; Ghorbani-Kalhor, E.; Hosseinzadeh-Khanmiri, R. RSC Adv. 2017, 7, 13198-13211. doi:10.1039/c7ra00746a

28. Gaber, H. M.; Bagley, M. C.; Muhammad, Z. A.; Gomha, S. M. RSC Adv. 2017, 7, 14562-14610. doi:10.1039/c7ra00683g

29. Roth, M.; Dubs, P.; Götschi, E.; Eschenmoser, A. Helv. Chim. Acta 1971, 54, 710-734. doi:10.1002/hlca.19710540229

30. Hussaini, S. R.; Chamala, R. R.; Wang, Z. Tetrahedron 2015, 71 , 6017-6086. doi:10.1016/j.tet.2015.06.026

31. Butler, D. E.; Nordin, I. C.; L'Italien, Y. J.; Zweisler, L.; Poschel, P. H.; Marriott, J. G. J. Med. Chem. 1984, 27, 684-691. doi:10.1021/jm00371a023

32. Knight, D. W.; Lewis, N.; Share, A. C.; Haigh, D. J. Chem. Soc., Perkin Trans. 1 1998, 3673-3684. doi:10.1039/a807313i

33. Cioc, R. C.; Schaepkens van Riempst, L.; Schuckman, P.; Ruijter, E.; Orru, R. V. A. Synthesis 2017, 49, 1664-1674. doi:10.1055/s-0036-1588672

34. Célérier, J.-P.; Deloisy-Marchalant, E.; Lhommet, G. J. Heterocycl. Chem. 1984, 21, 1633-1635. doi:10.1002/jhet.5570210611

35. Kappe, C. O. Chem. Soc. Rev. 2008, 37, 1127-1139. doi:10.1039/b803001b

36. Polshettiwar, V.; Varma, R. S. Acc. Chem. Res. 2008, 41, 629-639. doi:10.1021/ar700238s

37. Kappe, C. O. Angew. Chem., Int. Ed. 2004, 43, 6250-6284. doi:10.1002/anie.200400655

38. Kozerski, L. Org. Magn. Reson. 1977, 9, 395-400. doi:10.1002/mrc.1270090705

39. Alt, G. H.; Speziale, A. J. J. Org. Chem. 1965, 30, 1407-1409. doi:10.1021/jo01016a014

40. Pal, R.; Sarkar, T.; Khasnobis, S. ARKIVOC 2012, No. i, 570-609. doi:10.3998/ark.5550190.0013.114

41. Cho, H.; Török, F.; Török, B. Green Chem. 2014, 16, 3623-3634 doi:10.1039/c4gc00037d

42. Kumar, B. S.; Dhakshinamoorthy, A.; Pitchumani, K. Catal. Sci. Technol. 2014, 4, 2378-2396. doi:10.1039/c4cy00112e 43. Kaur, N.; Kishore, D. J. Chem. Pharm. Res. 2012, 4, 991-1015.

44. Baghernejad, B. Lett. Org. Chem. 2010, 7, 255-268. doi:10.2174/157017810791112487 
45. Clark, J. H.; Comerford, J. W.; Macquarrie, D. J. Green Catalytic Transformations. In Innovations in Green Chemistry and Green Engineering; Anastas, P. T.; Zimmerman, J. B., Eds.; Springer: New York, USA, 2012; p 67. doi:10.1007/978-1-4614-5817-3_3

46. Cho, H.; Schäfer, C.; Török, B. Microwave-Assisted Solid Acid Catalysis. In Microwaves in Catalysis: Methodology and Applications; Horikoshi, S.; Serpone, N., Eds.; Wiley-VCH: Weinheim, Germany, 2016; pp 193-212. doi:10.1002/9783527688111.ch10

47. Varma, R. S.; Baig, R. B. N. Organic Synthesis Using Microwaves and Supported Reagents. In Microwaves in Organic Synthesis, 3rd ed.; de la Hoz, A.; Loupy, A., Eds.; Wiley-VCH: Weinheim, Germany, 2012; pp 427-486. doi:10.1002/9783527651313.ch10

48. Hussaini, S. R.; Kuta, A.; Pal, A.; Wang, Z.; Eastman, M. A.; Duran, R. ACS Omega 2020, 5, 24848-24853. doi:10.1021/acsomega.0c03554

49. Klintworth, R.; de Koning, C. B.; Michael, J. P. J. Org. Chem. 2020, 85, 1054-1061. doi:10.1021/acs.joc.9b02983

50. Klintworth, R.; de Koning, C. B.; Michael, J. P. Eur. J. Org. Chem. 2020, 3860-3871. doi:10.1002/ejoc.202000499

51. Klintworth, R.; de Koning, C. B.; Opatz, T.; Michael, J. P. J. Org. Chem. 2019, 84, 11025-11031. doi:10.1021/acs.joc.9b01604

52. Xu, L.; Wu, L.; Chen, T.; Xu, S.; Huang, C.; Wang, Y.; You, Q.; Shen, J. ChemistrySelect 2020, 5, 655-659. doi:10.1002/slct.201903792

53. Gupton, J. T.; Crawford, E.; Mahoney, M.; Clark, E.; Curry, W.; Lane, A.; Shimozono, A.; Moore-Stoll, V.; Elofson, K.; Juekun, W.; Newton, M.; Yeudall, S.; Jaekle, E.; Kanters, R.; Sikorski, J. A. Tetrahedron 2018, 74, 7408-7420. doi:10.1016/j.tet.2018.10.078

54. Jumina; Keller, P. A.; Kumar, N.; Black, D. S. Tetrahedron 2008, 64, 11603-11610. doi:10.1016/j.tet.2008.10.025

55. Gupton, J. T.; Shimozono, A.; Crawford, E.; Ortolani, J.; Clark, E.; Mahoney, M.; Heese, C.; Noble, J.; Perez Mandry, C.; Kanters, R.; Dominey, R. N.; Goldman, E. W.; Sikorski, J. A.; Fisher, D. C. Tetrahedron 2018, 74, 2650-2663. doi:10.1016/j.tet.2018.04.017

56. Mathew, P.; Prasidha, M.; Asokan, C. V. J. Heterocycl. Chem. 2010, 47, 430-435. doi:10.1002/jhet.334

57. Fabbri, C.; Bietti, M.; Lanzalunga, O. J. Org. Chem. 2005, 70, 2720-2728. doi:10.1021/jo047826u

58. Chapman, N. B.; Clarke, K.; Harvey, D. J. J. Chem. Soc. C 1971, 1202-1206. doi:10.1039/j39710001202

59. Thomé, I.; Besson, C.; Kleine, T.; Bolm, C. Angew. Chem., Int. Ed. 2013, 52, 7509-7513. doi:10.1002/anie.201300917

60. Low, D. W.; Pattison, G.; Wieczysty, M. D.; Churchill, G. H.; Lam, H. W. Org. Lett. 2012, 14, 2548-2551. doi:10.1021/ol300845q

61. Li, X.-C.; Ferreira, D.; Jacob, M. R.; Zhang, Q.; Khan, S. I.; EISohly, H. N.; Nagle, D. G.; Smillie, T. J.; Khan, I. A.; Walker, L. A.; Clark, A. M. J. Am. Chem. Soc. 2004, 126, 6872-6873. doi:10.1021/ja048081c

62. Laufer, S.; Striegel, H. G.; Neher, K.; Zechmeister, P.; Donat, C.; Stolingwa, K.; Baur, S.; Tries, S.; Kammermeier, T.; Dannhardt, G.; Kiefer, W. Arch. Pharm. 1997, 330, 307-312. doi:10.1002/ardp.19973300908

63. Farag, A. M.; Hassaneen, H. M.; Abbas, I. M.; Shawali, A. S.; Algharib, M. S. Phosphorus Sulfur Relat. Elem. 1988, 40, 243-249. doi:10.1080/03086648808072921

64. Gharpure, S. J.; Anuradha, D.; Prasad, J. V. K.; Rao, P. S. Eur. J. Org. Chem. 2015, 86-90. doi:10.1002/ejoc.201403294

65. Dunn, N. L.; Ha, M.; Radosevich, A. T. J. Am. Chem. Soc. 2012, 134, 11330-11333. doi:10.1021/ja302963p
66. Chung, J. Y. L.; Hughes, D. L.; Zhao, D.; Song, Z.; Mathre, D. J.; Ho, G.-J.; McNamara, J. M.; Douglas, A. W.; Reamer, R. A.; Tsay, F.-R.; Varsolona, R.; McCauley, J.; Grabowski, E. J. J.; Reider, P. J. J. Org. Chem. 1996, 61, 215-222. doi:10.1021/jo951214f

67. Li, X.; McCoy, K. A.; Murray, W. V.; Jolliffe, L.; Pulito, V. Bioorg. Med. Chem. Lett. 2000, 10, 2375-2377. doi:10.1016/s0960-894x(00)00472-8

68. Brown, H. C.; Brewster, J. H.; Shechter, H. J. Am. Chem. Soc. 1954, 76, 467-474. doi:10.1021/ja01631a041

69. Brown, H. J. Org. Chem. 1957, 22, 439-441. doi:10.1021/jo01355a600

70. Fukuda, T.; Ishibashi, F.; Iwao, M. Lamellarin alkaloids: Isolation, synthesis, and biological activity. In The Alkaloids. Chemistry and Biology; Knölker, H.-J., Ed.; Academic Press: Cambridge, MA, USA, 2020; Vol. 83, pp 1-112. doi:10.1016/bs.alkal.2019.10.001

71. Handy, S. T.; Zhang, Y.; Bregman, H. J. Org. Chem. 2004, 69, 2362-2366. doi:10.1021/jo0352833

\section{License and Terms}

This is an Open Access article under the terms of the Creative Commons Attribution License (https://creativecommons.org/licenses/by/4.0). Please note that the reuse, redistribution and reproduction in particular requires that the author(s) and source are credited and that individual graphics may be subject to special legal provisions.

The license is subject to the Beilstein Journal of Organic Chemistry terms and conditions: (https://www.beilstein-journals.org/bjoc/terms)

The definitive version of this article is the electronic one which can be found at: $\underline{\text { https://doi.org/10.3762/bjoc. } 17.170}$ 